\title{
Profissionais de Psicologia na política de adoção: produção científica nacional
}

\section{Psychology Professionals in Adoption Policy: National Scientific Production}

\author{
Leonam Amitaf Ferreira Pinto de Albuquerque (orcid.org/0000-0003-1075-8344)'1 \\ Maria de Fátima Pereira Alberto (orcid.org/0000-0003-2515-9571)²
}

\begin{abstract}
Resumo
Este estudo tem por objetivo mapear a produção científica nacional sobre a atuação dos profissionais de Psicologia na política de adoção. Por meio de levantamento nas bases SciELO e Plataforma de Periódicos da Capes, com os descritores adoção e Psicologia, entre 2010 e 2017, foram recuperados 28 artigos, sendo encontradas definições de família tradicionais e não normativas. O conceito de adoção foi abordado sob diferentes perspectivas e foram apontadas conquistas e desafios do direito à convivência familiar. A preparação foi concebida como espaço de reflexão para os pretendentes e seus familiares. A equipe pode contribuir para a reintegração familiar. Conclui-se que os temas elencados perpassam a inserção da Psicologia no campo do direito à convivência familiar, contribuindo para a compreensão da atuação dos profissionais de Psicologia sob uma perspectiva crítica.
\end{abstract}

Palavras-chave: Psicólogos. Adoção. Política pública.

\begin{abstract}
This study aims to map the national scientific production on the performance of Psychology professionals in adoption policy. In total, 28 articles were retrieved by a survey in SciELO and Plataforma de Periódicos da CAPES databases, with the descriptors "adoption" and "psychology", between 2010 and 2017,. We found traditional and non-normative family definitions. The concept of adoption was approached from different perspectives. Achievements and challenges of the right to live in a family environment were pointed out. The preparation was conceived as a space for reflection for the applicants and their families. The team can contribute to the family reintegration. We concluded that the topics listed permeate the insertion of Psychology in the field of the right to live in a family environment, contributing to the understanding of the performance Psychology professionals from a critical perspective.
\end{abstract}

\footnotetext{
${ }^{1}$ Universidade Federal da Paraíba, João Pessoa, Brasil. E-mail: leonamamitaf2@hotmail.com.

2 Universidade Federal da Paraíba, João Pessoa, Brasil. E-mail: jfalberto89@gmail.com.
} 
Keywords: Psychologists. Adoption. Public policy.

Os programas de pós-graduação das universidades públicas brasileiras são um dos maiores responsáveis pela produção científica nacional, como apontam alguns indicadores (Coordenação de Aperfeiçoamento de Pessoal de Nível Superior [CAPES], 2010, 2014). Segundo Costa e Yamamoto (2015), o crescimento do Brasil em número de publicações científicas, nos últimos anos, reflete o desenvolvimento de políticas governamentais empreendidas nesse âmbito, considerado polo da atividade científica do país.

Yamamoto, Tourinho, Bastos e Menandro (2012) sustentam que a qualidade da pósgraduação brasileira é resultante do financiamento assumido pelas agências de fomento e do acompanhamento realizado pela Capes. Com base nas orientações dos planos nacionais de pós-graduação, o sistema avaliativo foi implantado e, ao longo das décadas, aperfeiçoado com ênfase na qualidade da avaliação, o que resultou no deslocamento da centralidade da docência para a pesquisa (Kuenzer \& Moraes, 2005).

A ciência nacional acompanhou as transformações desse cenário, marcado pelo "produtivismo", isto é, a adoção de parâmetros avaliativos que privilegiam a quantidade de produção do pesquisador em detrimento da qualidade e relevância (Bianchetti \& Sguissardi, 2009). Na mesma direção, a Psicologia configura-se, atualmente, como a segunda maior área das Ciências Humanas, com 77 programas de pós-graduação (Capes, 2014) e 11.764 publicações no triênio 2010-2012 (Bastos, Andery \& Trindade, 2013).

Em meio à lógica da "escalada produtivista", Yamamoto et al. (2012) reforçam que a atividade científica ultrapassa a validação dos resultados da pesquisa, uma vez que faz parte do compromisso social do pesquisador. Do mesmo modo, Costa e Yamamoto (2015) questionam como os domínios investigativos da Psicologia contribuem para o desenvolvimento da área, o que os remete ao emprego das publicações como ferramentas da prática profissional.

Ao analisar os 50 anos da profissão de psicólogo no Brasil, Yamamoto (2012) aborda o controverso campo do compromisso da Psicologia com a mudança social, o qual esbarra nas expressões da questão social, problemática resultante do sistema de produção 
capitalista. Segundo o autor, a contribuição da Psicologia para o processo de transformação social requer a proposição de um projeto ético-político que aponte para a transformação estrutural da sociedade capitalista, e não a sua manutenção, como ocorre no setor do bemestar social.

De forma semelhante às políticas sociais, que apresentam respostas parciais e fragmentadas às refrações da questão social, como a pobreza e a desigualdade social, a política pública de adoção garante, de modo pontual, o direito das crianças e adolescentes à filiação e à convivência familiar e comunitária (lamamoto, 2010). A partir da promulgação do Estatuto da Criança e do Adolescente (ECA), e com a criação da Lei n. 12.010, de 3 de agosto de 2009, que altera esse Estatuto, conhecida como Lei Nacional da Adoção, embora trate mais do direito à reinserção familiar, a Psicologia tem sido chamada a contribuir, ao lado de outras ciências e profissões, a exemplo do Serviço Social, como executora final desse tipo de política segmentada (Yamamoto, 2012).

As normativas sobre o direito das crianças e adolescentes à convivência familiar e comunitária atribuem aos profissionais de Psicologia e Serviço Social diversas funções, entre outras que Ihes forem reservadas pela legislação local, como pode ser observado no art. 151 do ECA (Lei n. 8.069, 1990): “fornecer subsídios por escrito, mediante laudos, ou verbalmente, na audiência, e bem assim desenvolver trabalhos de aconselhamento, orientação, encaminhamento, prevenção e outros, tudo sob a imediata subordinação à autoridade judiciária, assegurada a livre manifestação do ponto de vista técnico".

No caso específico dos profissionais de Psicologia, essas atribuições legais, ao mesmo tempo em que ampliam suas possibilidades de atuação, permitindo-Ihes agir nos meandros da política de adoção, geram sobrecarga de trabalho e contribuem para a reprodução das expressões da questão social nesse contexto (Oliveira \& Yamamoto, 2014). Sob esses aspectos, o presente estudo tem por objetivo mapear a produção científica nacional sobre a atuação dos profissionais de Psicologia na política de adoção, por meio de levantamento nas bases SciELO e Plataforma de Periódicos da Capes, com os descritores adoção e Psicologia, entre 2010 e 2017. 


\section{Método}

Tipo de estudo

Trata-se de um levantamento da produção científica nacional, que permite o resumo, a análise e a síntese das informações disponibilizadas pela produção científica sobre variados temas de interesse. Essa modalidade de estudo bibliográfico não exige uma metodologia predefinida, com procedimentos rígidos de seleção de artigos e trabalhos. Seu emprego contribui para o desenvolvimento científico das áreas de estudo, no campo da pesquisa (Mancini \& Sampaio, 2006).

\section{Bases indexadoras e descritores}

A Scientific Electronic Library Online (SciELO) foi escolhida como base de dados por ser uma biblioteca eletrônica gratuita, de fácil acessibilidade ao texto completo de artigos publicados em periódicos científicos brasileiros; e a Plataforma de Periódicos da Capes foi adotada como fonte de busca por ser aberta à comunidade acadêmica e possibilitar o acesso ao texto completo de trabalhos de dissertação e tese. Foram utilizados como descritores o termo "adoção" e sua combinação, por meio do operador booleano "and", com o termo "Psicologia".

\section{Critérios de inclusão e exclusão}

Os critérios de inclusão dos estudos foram: a) artigos indexados; b) trabalhos de dissertação e tese; c) disponíveis na íntegra; d) redigidos em língua portuguesa; e) publicados no período entre 2010 e 2017; e f) que abordam o objeto de estudo do levantamento. Os critérios de exclusão dos estudos foram: a) artigos não indexados, livros, capítulos de livros, monografias, resenhas, cartas, obituários, resumos, atas de congressos e notícias; b) disponíveis de forma parcial; c) redigidos em língua estrangeira; d) publicados 
em período anterior a 2010; e) que não abordam o objeto de estudo do levantamento; e f) repetidos.

\section{Procedimentos}

O levantamento nas bases SciELO e Plataforma de Periódicos da Capes ocorreu no período entre agosto de 2017 e janeiro de 2018. Os artigos e trabalhos científicos foram, inicialmente, selecionados por meio da busca por assunto com o descritor "adoção". Foi realizado, então, um refinamento da procura, por meio do operador booleano "and", com o acréscimo, na busca por assunto, do descritor "Psicologia".

Os resumos encontrados a partir da busca por assunto com os descritores e sua combinação foram submetidos a uma leitura minuciosa, excluindo-se os estudos que não atendiam aos critérios de inclusão adotados. Os trabalhos resultantes dessa etapa foram examinados e lidos na íntegra, retirando-se aqueles que se enquadravam nos critérios de exclusão elencados. Os artigos recuperados nessa última fase constituíram o corpus de análise do presente levantamento.

\section{Resultados e discussão}

Na biblioteca eletrônica SciELO, como resultado da busca por assunto com o descritor "adoção", foram encontrados 1.469 artigos. Ao se associar, por meio do operador booleano "and", os descritores "adoção" e "Psicologia", foram reunidos 69 artigos. No Portal de Periódicos da Capes, como resultado da busca por assunto com o descritor "adoção", foram encontrados 4.346 trabalhos, entre artigos, dissertações e teses. Ao se agregar, por meio do operador booleano "and", os descritores "adoção" e "Psicologia", foram reunidos 565 trabalhos, todos no formato de artigo.

A partir da aplicação dos critérios de inclusão e exclusão e da retirada dos estudos repetidos, foram recuperados, no total, 28 artigos $(n=28)$, os quais se encontram caracterizados, no Quadro 1, em termos de ano de publicação, tipo de estudo e abordagem 
utilizada. $\mathrm{O}$ ano de publicação remete ao período no qual o artigo foi publicado; o tipo de estudo refere-se ao enquadramento formal do artigo como relato de estudo empírico, revisão teórica, estudo de caso etc.; a abordagem utilizada corresponde aos procedimentos qualitativos, quantitativos ou quali-quantitativos adotados nos artigos de relato de estudo empírico e estudo de caso.

Tabela 1. Caracterização dos artigos recuperados em termos de ano de publicação, tipo de estudo e abordagem utilizada $\left(n^{*}=28\right)$

\begin{tabular}{|l|l|l|}
\hline Ano & Tipo & Abordagem \\
\hline $2010(n=3)$ & Estudo de caso $(n=8)$ & Qualitativa $(n=17)$ \\
$2011(n=1)$ & Revisão teórica $(n=9)$ & Quantitativa $(n=2)$ \\
$2012(n=3)$ & Estudo empírico $(n=11)$ & \\
$2013(n=7)$ & & \\
$2014(n=3)$ & & \\
$2015(n=3)$ & & \\
$2016(n=4)$ & & \\
$2017(n=4)$ & & \\
\hline
\end{tabular}

"Quantidade de elementos da amostra.

Fonte: Elaborado pelos autores.

No que se refere ao ano de publicação, pode-se observar que a maior parte dos artigos recuperados foi publicada em $2013(n=7)$, três anos depois do início do período de vigência da Lei n. 12.010/09, em $2010(n=3)$, que altera o ECA e dispõe sobre o aperfeiçoamento da sistemática prevista para garantia do direito à convivência familiar a todas as crianças e adolescentes. Convém ressaltar a quantidade mínima de artigos publicados no ano posterior à vigência dessa alteração no ECA, em $2011(n=1)$. Percebe-se também a regularidade do número de publicações no período consultado, com uma média de 3,5 produções por ano.

Quanto ao tipo de estudo, pode-se notar que a maioria dos artigos recuperados enquadra-se no formato de relato de estudo empírico $(n=11)$, o que denota uma diferença pouco significativa em relação ao número de artigos publicados nos formatos de estudo de caso $(n=8)$ e revisão teórica $(n=9)$, que também apresentaram quantidades elevadas. No 
que diz respeito à abordagem utilizada nos artigos de relato de estudo empírico $(n=11)$ e estudo de caso ( $n=08)$, nota-se uma prevalência de procedimentos qualitativos $(n=17)$, em detrimento de procedimentos quantitativos $(n=2)$ e quali-quantitativos. Esses últimos consistem na articulação entre metodologias qualitativas e quantitativas em uma mesma pesquisa, não sendo identificada sua presença nos estudos consultados.

Com vistas a possibilitar a análise dos resultados encontrados, os 28 artigos recuperados no levantamento foram classificados em cinco unidades temáticas: 1 . Definições de família. 2. Conceitos de adoção. 3. Legislação sobre adoção. 4. Preparação para a adoção. 5. Equipe interprofissional. Os temas elencados perpassam a inserção da Psicologia no campo da garantia do direito das crianças e adolescentes à convivência familiar e comunitária, contribuindo para a compreensão da atuação dos profissionais de Psicologia na política de adoção sob um viés crítico.

Neste estudo, adota-se a Psicologia sócio-histórica como referencial teórico, comprometida com a crítica da visão hegemônica de homem na Psicologia e da naturalização do fenômeno psicológico como algo abstrato e universal, que reside tão somente no indivíduo, de forma a responsabilizá-lo por seu próprio desenvolvimento. Essa perspectiva crítica concebe o homem como sujeito ativo, social e histórico, constituído e, portanto, constituinte das práticas sociais, o que implica na apreensão dialética da realidade social na sua totalidade e complexidade, contemplando seus movimentos e contradições (Alberto, 2012).

\section{Definições de família}

As transformações ocorridas nas sociedades capitalistas ocidentais a partir da segunda metade do século $\mathrm{XX}$, decorrentes do processo de industrialização, alteraram as características da estrutura e dinâmica familiares vigentes, de caráter patriarcal. No que diz respeito à divisão de papeis sociais entre homens e mulheres, por exemplo, observou-se, ao longo das décadas, um relativo crescimento da participação da figura masculina nos 
afazeres domésticos e um lento processo de abertura do mercado de trabalho para a figura feminina (Rosa, Boris, Melo \& Santos, 2016).

Cecílio e Scorsolini-Comin (2013) e Santos, Scorsolini-Comin e Santos (2013) caracterizam a família nuclear burguesa como o modelo predominante nas sociedades capitalistas patriarcais, marcado por aspectos hegemônicos, como a heteronormatização e a consanguinidade. Sobre a heteronormatividade, Bento (2017) compreende esse processo, a partir da noção de performances normativas (Butler, 2008), como a produção e reiteração da norma heterossexual, que se inscreve na lógica de manutenção da continuidade e da coerência entre sexo, gênero e sexualidade. Em contraste, Machin (2016) descreve os arranjos familiares não normativos, insurgentes na luta de classes entre capital e trabalho, como uma diversidade de configurações, a exemplo das famílias homoparentais, monoparentais e reconstituídas, caracterizadas, de acordo com Kehl (2013), pelo estabelecimento de relações tentaculares de independência e proximidade entres seus membros, com abertura para acolher novos integrantes, advindos de outras formações familiares.

De acordo com Cecílio e Scorsolini-Comin (2016), a emergência dessas composições familiares não convencionais implicou em alterações nas definições contemporâneas de família, cuja análise exige um olhar ampliado a partir das funções parentais e dos papéis de gênero. Nesse sentido, para Rosa et al. (2016), a instituição social familiar não pode mais ser definida no singular, como um modelo único, normatizado e universal, mas sim no plural, de modo a contemplar as vicissitudes e diversidades das configurações familiares emergentes.

No cenário nacional, conforme Silva e Arpini (2013), persiste a dificuldade em respeitar as peculiaridades de formação dos arranjos familiares não tradicionais e em reconhecer seu lugar na sociedade, com a imposição de valores familiares tradicionais. Para Machin (2016), esse processo está relacionado à prevalência de um sistema de código relacional no país, baseado na hierarquia das posições de classe social, intersectada por questões de raça, gênero, diversidade sexual etc., perante as quais a instituição familiar se apresenta como um valor absoluto que perpassa a história e todas as instâncias da sociedade. 
Santos et al. (2013) enfatizam que as composições familiares não normativas constituem um desafio para as áreas convencionais do conhecimento científico, uma vez que a maior parte de seus fundamentos epistemológicos está assentada sob o modelo hegemônico de família. Alguns dos artigos recuperados pautam-se em referenciais teóricos pertencentes a diferentes áreas do saber para apresentar definições de família que se aproximam do modelo tradicional burguês ou da perspectiva contemporânea das configurações familiares não normativas.

Entre os artigos que propõem definições de família próximas do modelo tradicional, Montenegro, Rocha e Francileudo (2017) argumentam que a instituição familiar proporciona condições básicas de proteção e afeto aos seus membros, sob pena de gerar disfunções familiares. No mesmo sentido, segundo Otuka, Scorsolin-Comin e Santos (2012), a família constitui um receptáculo das angústias destrutivas inconscientes, as quais cedem espaço às possibilidades de encontro, aprendizado e construção parental de laços afetivos.

Entre aqueles cujas definições se aproximam das configurações familiares não normativas, Cecílio, Scorsolini-Comin e Santos (2013) apontam para uma maior preocupação da literatura nacional em apresentar definições de família condizentes com seus diversos contornos. Para Cecílio e Scorsolini-Comin (2013), não somente as figuras parentais se encontram em período de transição de papéis, mas também a instituição familiar, em razão da construção da conjugalidade e da parentalidade e da emergência de arranjos familiares não tradicionais.

\section{Conceitos de adoção}

O conceito de adoção recebeu inúmeros significados ao longo da história, em razão das divergências entre os antigos códigos morais, as leis vigentes e os dogmas religiosos e das diferenças de formação sociocultural entre as sociedades capitalistas ocidentais (Teixeira Filho, 2010). Etimologicamente, segundo Amazonas, Veríssimo e Lourenço (2013), o termo adotar advém do latim adoptare e significa perfilhar, o que remete à inserção de 
crianças e adolescentes em famílias substitutas, as quais assumem a responsabilidade legal pelos seus cuidados.

Valério e Lyra (2014) enfatizam que, apesar da escassez de estudos sobre os significados atribuídos à adoção, sua definição adquiriu novos contornos nos últimos anos, em decorrência dos avanços na legislação sobre filiação e na política pública de adoção. Entre os diversos significados existentes, os autores Rosa et al. (2016), Luz, Gelain e Amaral (2014), Otuka, Scorsolini-Comin e Santos (2013), Oliveira e Próchno (2010) e Machin (2016) definem a adoção sob as perspectivas jurídica, psicanalítica, humanista e construcionista.

A partir do viés jurídico, Rosa et al. (2016) compreendem a adoção como uma medida que garante a toda criança ou adolescente o direito de ser criado por sua família de origem, e, em condições especiais, por famílias substitutas ou instituições de acolhimento, durante período não superior a 18 meses. Segundo Luz et al. (2014), esse instituto jurídico possibilita que crianças ou adolescentes, sem vínculos biológicos de parentesco com os adotantes, se tornem irrevogavelmente seus filhos, com os mesmos direitos e deveres, inclusive sucessórios.

Com base no olhar psicanalítico, Otuka et al. (2013) definem a adoção a partir dos problemas relacionados à colocação em família substituta e ao manejo da relação com a criança ou adolescente, o que implica aspectos clínicos, sociais e legais. Os autores acrescentam que a adoção costuma se configurar como uma experiência positiva para os adotantes, sob a condição de que estes se consolidem como uma instância familiar suficientemente boa para seus novos membros (Otuka et al., 2012).

Sob a perspectiva humanista, Oliveira e Próchno (2010) conceituam a adoção como uma prática humanitária, caracterizada pelo acolhimento de crianças ou adolescentes abandonados em lares substitutos, que possam lhes oferecer cuidado, educação e proteção. Por sua vez, a partir do olhar construcionista, Machin (2016) define a adoção como uma categoria histórica, chancelada pelo Estado com o objetivo de inserir crianças ou adolescentes abandonados em famílias adotivas capazes de lhes propiciar um ambiente adequado. 


\section{Legislação sobre adoção}

Silva e Arpini (2013) e Siqueira (2012) analisam a garantia do direito das crianças e adolescentes à convivência familiar e comunitária como uma estratégia do Estado para superar a cultura da institucionalização de crianças e adolescentes. Para esses autores, as recentes conquistas no campo da legislação sobre a infância e adolescência refletem o resgate da centralidade do papel do Poder Público, da família e da sociedade nas políticas públicas de proteção integral dos direitos das crianças e adolescentes.

Sob a doutrina da situação irregular, o antigo Código de Menores, de 1979, estabeleceu estratégias de controle dos chamados "menores", categoria de crianças e adolescentes considerados suspeitos pelo Estado e potencialmente perigosos para a sociedade, numa associação do perigo com a pobreza (Santos, 2014), entre elas, dividir o instituto da adoção nas modalidades simples e plena, de acordo com a situação jurídica regular ou não da criança ou adolescente (Maux \& Dutra, 2010). Como explica Darós (2016), a adoção simples atribuía a condição de filho ao adotado, podendo esta ser anulada, e não reconhecia seus direitos sucessórios, diferentemente da adoção plena, que previa os mesmos direitos e deveres dos demais membros familiares e era irrevogável. Em direção contrária, o ECA e suas alterações legais ampliaram a garantia do direito à convivência familiar e comunitária para todas as crianças e adolescentes, independentemente da classe social de suas famílias (Andrade, Hueb \& Alves, 2017).

Luz et al. (2014) não concordam com a diminuição do prazo de decisão das autoridades judiciárias, prevista na Lei n. 12.010/09, que altera o ECA, uma vez que a maioria das instituições de acolhimento não apresenta condições de suprir as novas demandas. Por sua vez, para Rossetti-Ferreira et al. (2012), essa alteração no texto do Estatuto repercutiu na criação de políticas de proteção integral, as quais têm exercido papel importante no movimento de desinstitucionalização de crianças e adolescentes. 


\section{Preparação para a adoção}

Conforme Morelli, Scorsolini-Comin e Santeiro (2015), a etapa preparatória não se restringe à aquisição de informações, mas também corresponde à construção da parentalidade adotiva pelos pretendentes, tal como ocorre com os pais biológicos na gestação. Cecílio e Scorsolini-Comin (2016) reforçam que essa fase de transição parental constitui um momento importante no ciclo vital dos pretendentes, em razão da ampliação dos papeis conjugais, com a assunção de tarefas, a fim de responder às necessidades dos novos membros familiares.

Para Valério e Lyra (2014), o período de preparação para a adoção configura-se como um espaço permanente de reflexão, que implica diretamente não apenas os pretendentes à adoção como também os membros de sua família extensa, pois estes também estão envolvidos no processo de filiação. Nesse sentido, Silva e Arpini (2013) enfatizam as dificuldades do processo de reintegração familiar e comunitária de crianças e adolescentes e apontam para a necessidade de que suas famílias também sejam assistidas por profissionais capacitados e equipes multidisciplinares, formadas por psicólogos, assistentes sociais, entre outros.

Morelli et al. (2015) chamam atenção para os Grupos de Apoio à Adoção (GAA) como meios de preparação para a adoção, os quais podem auxiliar os pretendentes na compreensão dos desafios, preconceitos, fantasias e receios pertinentes à adoção. De acordo com Cecílio e Scorsolini-Comin (2013), esse tipo de grupo pode proporcionar aos pretendentes um espaço de intercâmbio de experiências, expectativas e esclarecimentos sobre o processo de adoção, além de disseminar sua cultura e oferecer suporte emocional.

\section{Equipe interprofissional}

Segundo Valério e Lira (2014), a atuação de profissionais nos casos de adoção é um dos temas mais presentes na literatura nacional sobre adoção, ao lado das motivações dos pretendentes para adotar e dos significados atribuídos pelas famílias substitutas à adoção. 
Teixeira Filho (2010) questiona até que ponto os critérios de avaliação adotados e o corpo teórico em que esses profissionais pautam sua prática podem contribuir para perpetuar preconceitos e estigmas sobre o instituto da adoção entre os interessados.

De acordo com Silva e Arpini (2013), a equipe interprofissional da Vara da Infância e Juventude costuma ser formada por profissionais de Psicologia e Serviço Social, que acompanham os processos de manutenção e reintegração de crianças e adolescentes às famílias de origem, respectivamente, antes das medidas de colocação em família substituta e acolhimento institucional e depois dessa última. Esses profissionais também podem estimular a participação dos pretendentes no processo de adoção, tendo em vista as implicações do envolvimento afetivo destes com a filiação sobre o desenvolvimento das crianças e adolescentes (Bueno, Viera \& Crepaldi, 2017).

Segundo Coimbra (2014), a Justiça da Infância e Juventude é responsável por reconhecer os pretendentes à adoção como pais legítimos das crianças e adolescentes, o que acarreta inúmeras funções para os membros da equipe no seu exercício profissional na política pública de adoção. Para Morelli et al. (2015), os profissionais que atuam nessa política, entre psicólogos, assistentes sociais e outros, são levados a realizar um exercício permanente de reflexão sobre as implicações de suas decisões sobre a vida das crianças e adolescentes e suas famílias.

Cecílio et al. (2013) chamam atenção para a importância da atuação da equipe interprofissional com as famílias substitutas, a fim de promover ambientes facilitadores, nos quais pretendentes e adotandos possam se vincular e compartilhar experiências. No mesmo sentido, Cecílio e Scorsolini-Comin (2013) ressaltam a colaboração de equipes interdisciplinares na construção de vínculos entre os pais adotivos e seus filhos, a fim de garantir um ambiente seguro e saudável para o desenvolvimento da criança ou adolescente.

A atuação dos profissionais de Psicologia na política pública de adoção não pode ser vista como neutra, pois é orientada por conceitos, valores e concepções de caráter pessoal, ético, profissional e ideológico (Cecílio et al., 2013; Silva \& Arpini, 2013). Esses fatores podem determinar a procura por modelos hegemônicos de família, baseados em valores 
tradicionais, não condizentes com a realidade social das crianças e adolescentes e suas famílias de origem (Amazonas et al., 2013; Sousa \& Paravidini, 2011).

Do mesmo modo, a atuação desses profissionais nessa política é permeada por conceitos convencionais de adoção, relacionados à cultura da institucionalização, que podem determinar a busca por crianças e adolescentes que se adéquem aos interesses das famílias substitutas (Maux \& Dutra, 2010). A compreensão do modo como o processo de adoção se concretiza nas configurações familiares atuais constitui uma ferramenta fundamental de trabalho, pois auxilia na identificação dos significados e sentidos atribuídos à adoção pelos envolvidos (Otuka et al., 2012).

Convém ressaltar a importância de os profissionais de Psicologia terem conhecimento das leis vigentes sobre os direitos das crianças e adolescentes e, em particular, da legislação sobre a adoção, de modo a contribuírem para sua operacionalização (Morelli et al., 2015). A implementação de políticas públicas de proteção integral dos direitos da infância e adolescência exige o trabalho em rede de equipes multiprofissionais, formadas por técnicos capacitados a partir de amplos conhecimentos (Siqueira, 2012).

Os profissionais de Psicologia da Vara da Infância e Juventude são responsáveis, em parceria com outros atores da política pública de adoção, como os profissionais de Serviço Social, pelo processo de preparação dos interessados para a adoção (Valério \& Lyra, 2014). A etapa preparatória inclui visitas e entrevistas, registro de informações, Grupo de Habilitação para Adoção (GHA) e acompanhamento dos pretendentes ao longo do processo de adoção e do estágio de convivência com as crianças ou adolescentes sob guarda provisória (Montenegro et al., 2017).

Entre as atividades desenvolvidas pela equipe interprofissional, estão a preparação dos pretendentes, a avaliação psicossocial e a realização de entrevistas e visitas domiciliares (Montenegro et al., 2017). Os documentos técnicos escritos resultantes dessas atividades auxiliam a autoridade judiciária a fundamentar as decisões referentes ao processo de adoção e à garantia do direito de crianças e adolescentes à convivência familiar e comunitária (Pereira, Torres, Falcão \& Pereira, 2013). 


\section{Considerações finais}

A partir da análise dos resultados encontrados, pode-se concluir que a maior parte dos 28 artigos recuperados no levantamento foi publicada no ano de 2013 e enquadra-se no formato de relato de estudo empírico, utilizando, principalmente, procedimentos qualitativos. Apesar da regularidade do número de publicações no período consultado, convém ressaltar a quantidade mínima de artigos publicados em 2011, ano posterior ao início do período de vigência da alteração no texto do ECA, que dispõe sobre o aperfeiçoamento da sistemática prevista para garantia do direito à convivência familiar a todas as crianças e adolescentes.

O número de artigos publicados nos formatos de estudo de caso e revisão teórica aproximou-se da quantidade de artigos publicados no formato de relato de estudo empírico, o que representou uma diferença pouco significativa quanto aos tipos de estudos encontrados; os artigos de relato de estudo empírico e de estudo de caso utilizaram-se minimamente de procedimentos quantitativos; a abordagem mista de procedimentos qualitativos e quantitativos, conhecida como quali-quantitativa, não foi identificada nos estudos consultados.

Os artigos recuperados no levantamento foram classificados em unidades temáticas: definições de família; conceitos de adoção; legislação sobre adoção; preparação para a adoção; e equipe interprofissional. Os temas elencados perpassam a inserção da Psicologia como ciência e profissão no campo da garantia do direito das crianças e adolescentes à convivência família e comunitária, oferecendo contribuições para a compreensão da atuação dos profissionais de Psicologia na política de adoção sob o viés crítico da Psicologia sóciohistórica.

Ao se reportarem à atuação dos profissionais de Psicologia na política de adoção, os artigos recuperados abordaram as definições de família que se aproximam do modelo tradicional burguês ou das configurações familiares não normativas. O conceito de adoção foi visto sob as perspectivas jurídica, psicanalítica, humanista e construcionista. Foram 
apontadas as conquistas e desafios no campo da garantia do direito à convivência familiar e comunitária. A etapa preparatória foi concebida como um espaço permanente de reflexão para os pretendentes à adoção e sua família extensa. A equipe interprofissional pode contribuir para a manutenção e reintegração de crianças e adolescentes a suas famílias de origem.

Enquanto as definições tradicionais de família situam essa instituição como uma instância de proteção e risco para seus membros, as definições contemporâneas a concebem a partir de seus diversos contornos. Sob a perspectiva jurídica, a adoção garante o direito à convivência familiar e comunitária; sob o olhar psicanalítico, remete aos inúmeros aspectos que permeiam a relação entre adotantes e adotandos; sob a perspectiva humanista, corresponde à prática humanitária de acolher crianças ou adolescentes abandonados; a partir do olhar construcionista, constitui uma categoria histórica, criada para inserir crianças ou adolescentes em famílias adotivas.

A garantia do direito das crianças e adolescentes à convivência familiar e comunitária é analisada como uma estratégia do Estado para superar a cultura da institucionalização. As conquistas no campo da legislação sobre a infância e adolescência, com a revogação do Código de Menores de 1979, sucessor da primeira norma menorista, de 1927, e a promulgação do ECA e sua alteração por meio da Lei n. 12.010/09, refletem o resgate do papel central das instituições sociais nas políticas de proteção dos direitos da infância e adolescência. Em meio às críticas à legislação sobre adoção, essas mudanças repercutiram na criação de políticas públicas voltadas para a desinstitucionalização de crianças e adolescentes.

O período de preparação para a adoção não se restringe à aquisição passiva de informações, pois compreende o complexo processo de construção da parentalidade adotiva pelos pretendentes. Essa fase de transição amplia os papeis parentais e as tarefas do(s) adotante(s) de modo a responder às necessidades dos membros familiares. A etapa preparatória constitui um espaço permanente de reflexão não apenas para os pretendentes à adoção como também para os membros de sua família extensa. Os Grupos de Apoio à 
Adoção podem auxiliar os participantes na compreensão dos inúmeros aspectos que permeiam a adoção, oferecendo espaço para o compartilhamento de experiências.

A prática de profissionais nos casos de adoção é um dos temas mais pesquisados na literatura nacional sobre adoção. Questiona-se em que medida os critérios técnicos de avaliação e o corpo teórico adotados contribuem para perpetuar preconceitos sobre adoção entre os interessados. A equipe interprofissional acompanha os processos de manutenção e reintegração de crianças e adolescentes às famílias de origem, respectivamente, antes das medidas de colocação em família substituta e acolhimento institucional e depois dessa última. Em meio às inúmeras atribuições, os profissionais de Psicologia e Serviço Social, que costumam compor as equipes da Vara da Infância e Juventude, precisam estar atentos às implicações de suas decisões sobre a vida das crianças e adolescentes e suas famílias de origem.

A atuação dos profissionais de Psicologia na política de adoção é orientada por múltiplos fatores que podem influenciar na busca por modelos hegemônicos de família, regidos por valores tradicionais, incompatíveis com o contexto familiar e comunitário das crianças e adolescentes em condições de serem adotados. De forma semelhante, a prática de uma parte desses profissionais é perpassada por conceitos ultrapassados de adoção, que desconsideram o direito das crianças e adolescentes à convivência familiar e comunitária em razão dos interesses dos pretendentes à adoção.

Com vistas a contribuírem para a operacionalização da política de adoção, os profissionais de Psicologia devem apresentar amplo conhecimento das leis vigentes sobre os direitos da infância e adolescência e da legislação sobre a adoção, como o ECA e a alteração no seu texto legal mediante a Lei n. 12.010/09. Os profissionais de Psicologia da Vara da Infância e Juventude atuam em conjunto com outros atores da política de adoção, como os profissionais de Serviço Social, no processo de preparação dos interessados para a adoção, etapa que envolve uma série de atribuições profissionais.

Entre as inúmeras atividades desempenhadas pelos membros da equipe interprofissional, são apontadas o período de preparação dos pretendentes à adoção, a avaliação psicossocial e a realização de entrevistas e visitas domiciliares. Os documentos 
técnicos resultantes dessas atividades auxiliam a autoridade judiciária a embasar as decisões tomadas, no que se refere ao processo de adoção e à garantia do direito de crianças e adolescentes à convivência familiar e comunitária.

A partir da análise dos artigos recuperados, depreende-se que a atuação dos profissionais de Psicologia na política de adoção pode reproduzir modelos tradicionais e naturalizados de família; a adoção pode ser pautada pelos interesses dos pretendentes em detrimento do direito das crianças e adolescentes à convivência familiar e comunitária; o conhecimento das leis vigentes sobre os direitos da infância e adolescência constitui uma ferramenta fundamental para a operacionalização da política de adoção; a etapa preparatória pode se configurar como um espaço de reflexão para os pretendentes à adoção e seus familiares, mas também como uma forma de enquadrá-los em modelos hegemônicos; as atividades desempenhadas pelos membros da equipe interprofissional oferecem subsídios técnicos para garantir o direito à convivência familiar e comunitária.

Convém, por fim, ressaltar que esse levantamento da produção científica nacional constitui um recorte do tema da atuação dos profissionais de Psicologia na política de adoção, apresentando algumas limitações, como a quantidade reduzida de bases consultadas e de descritores utilizados, o que configura um convite à complementação deste estudo por meio de buscas em outras fontes de dados e com outros termos mais abrangentes. Espera-se que os resultados apontados contribuam para o desenvolvimento de outras pesquisas na área, de caráter empírico e sob diferentes perspectivas teóricas, de modo a ampliar e aprofundar o conhecimento sobre a inserção da Psicologia como ciência e profissão no campo da garantia do direito de crianças e adolescentes à convivência familiar e comunitária.

\section{Referências}

Alberto, M. F. P. (2012). Pensamento crítico, formação de psicólogo e atuação junto à infância e adolescência. Estudos de Psicologia (Natal), l7(2), 421-426. Recuperado de http://dx.doi.org/10.1590/S1413-294X2012000300010. 
Amazonas, M. C., Veríssimo, H. V., \& Lourenço, G. O. (2013). A adoção de crianças por gays. Psicologia \& Sociedade, 25(3), 631-641. Recuperado em 20 agosto, 2017, de http://www.redalyc.org/pdf/3093/309329764017.pdf.

Andrade, L. C., Hueb, M. F., \& Alves, C. M. (2017). Era uma vez... um estudo de caso sobre histórias e estórias adotivas. Estudos de Psicologia (Campinas), 37(1), 173-183. Recuperado de https://doi.org/10.1590/1982-02752017000100017.

Bastos, A. V. B., Andery, M. A. P. A., \& Trindade, Z. A. (2013). Relatório de avaliação 20102012 - avaliação trienal 2013. Recuperado em 12 junho, 2018, de http://avaliacaotrienal2013.capes.gov.br/documento-de-area-e-comissao.

Bento, B. (2017).Transviad@s: gênero, sexualidade e direitos humanos. Salvador: EDUFBA.

Bianchetti, L., \& Sguissardi, V. (Orgs.). (2009). Dilemas da pós-graduação. Campinas: Autores Associados.

Bueno, R. K., Vieira, M. L., \& Crepaldi, M. A. (2017). Envolvimento paterno com filhos adotivos e a estrutura familiar. Psicologia: Teoria e Pesquisa, 33(1), 1-10. Recuperado de https://doi.org/10.1590/0102.3772e3342.

Butler, J. (2008). Cuerpos que importan: sobre los límites materiales y discursivos del "sexo". Buenos Aires: Paidós.

Cecílio, M. S., \& Scorsolini-Comin, F. (2013). Relações entre conjugalidade e parentalidades adotiva e biológica. Psico, 44(2), 245-256. Recuperado em 24 agosto, 2017, de http://revistaseletronicas.pucrs.br/revistapsico/ojs/index.php/revistapsico/article/vi ew/11515/9643.

Cecílio, M. S., \& Scorsolini-Comin, F. (2016). Parentalidades adotiva e biológica e suas repercussões nas dinâmicas conjugais. Psicologia: Ciência e Profissão, 36(1), 171182. Recuperado de https://doi.org/10.1590/1982-3703003832015.

Cecílio, M. S., Scorsolini-Comin, F., \& Santos, M. A. (2013). Produção científica sobre adoção por casais homossexuais no contexto brasileiro. Estudos de Psicologia (Natal), 18(3), 507-516. Recuperado de https://doi.org/10.1590/S1413-294X2013000300011. 
Coimbra, J. C. (2014). A demanda nos processos de habilitação para adoção e a função dos dispositivos judiciais. Estudos e Pesquisas em Psicologia, 5(2), 67-78. Recuperado em 30 maio, 2017, de http://pepsic.bvsalud.org/pdf/epp/v5n2/v5n2a08.pdf.

Coordenação de Aperfeiçoamento de Pessoal de Nível Superior - Capes. (2010). Países com maior número de artigos publicados em periódicos científicos indexados pela Thomson/ISI, 2009. Recuperado em 12 junho, 2018, de http://www.mct.gov.br/index.php/content/view/2078/Producao_cientifica.html.

Coordenação de Aperfeiçoamento de Pessoal de Nível Superior - Capes. (2014). Cursos recomendados e reconhecidos. Recuperado em 12 junho, 2018, de http://www.capes.gov.br/avaliacao/cursos-recomendados-e-reconhecidos.

Costa, J., \& Yamamoto, O. H. (2015). Produção científica em Psicologia nos cursos de graduação de psicólogos. Arquivos Brasileiros de Psicologia, 67(1), 20-36. Recuperado em 11 maio, 2018, de http://pepsic.bvsalud.org/scielo.php?script=sci_arttext\&pid=S18095267201500010 $0003 \& \operatorname{lng}=p t \& n r m=i s o \& t \operatorname{lng}=p t$.

Darós, L. E. S. (2016). Adoção judicial de filh@s por casais homossexuais: a heteronormatividade em questão. Tese de doutorado, Universidade do Estado do Rio de Janeiro, Rio de Janeiro, Brasil.

lamamoto, M. V. (2010). Questão social, família e juventude: desafios do trabalho do assistente social na área sociojurídica. In M. A. Sales, M. C. Matos \& M. C. Leal (Orgs.). Política social, família e juventude. Uma questão de direitos. São Paulo: Cortez.

Kehl, M. R. (2013). Em defesa da família tentacular. Recuperado em 25 setembro, 2020, de https://www.fronteiras.com/artigos/maria-rita-kehl-em-defesa-da-familiatentacular.

Kuenzer, A. Z., \& Moraes, M. C. M. (2005). Temas e tramas na pós-graduação em Educação. Educação \& Sociedade, 26(93), 1341-1362. Recuperado de https://doi.org/10.1590/S0101-73302005000400015. 
Lei n. 8.069, de 13 de julho de 1990. (1990). Dispõe sobre o Estatuto da Criança e do Adolescente e dá outras providências. Recuperado em 2 julho, 2020, de http://www.planalto.gov.br/ccivil_03/leis/l8069.htm.

Luz, A. F., Gelain, D., \& Amaral, L. M. (2014). Vivências das famílias na adoção tardia. Revista de Psicologia da IMED, 6(1), 52-57. Recuperado em 24 agosto, 2017, de https://dialnet.unirioja.es/descarga/articulo/5154964.pdf.

Machin, R. (2016). Homoparentalidade e adoção: (re)afirmando seu lugar como família. Psicologia \& Sociedade, 28(2), 350-359. Recuperado de https:// doi.org/10.1590/1807-03102016v28n2p350.

Mancini, M. C., \& Sampaio, R. F. (2006). Quando o objeto de estudo é a literatura: estudos de revisão. Revista Brasileira de Fisioterapia, 10(4), 361-472. Recuperado de https://doi.org/10.1590/S1413-35552006000400001.

Maux, A. A. B., \& Dutra, E. (2010). A adoção no Brasil: algumas reflexões. Estudos $e$ Pesquisas em Psicologia, 10(2), 356-372. Recuperado em 30 maio, 2017, de http://pepsic.bvsalud.org/pdf/epp/v10n2/v10n2a05.pdf.

Montenegro, A. F., Rocha, L. D., \& Francileudo, F. A. (2017). Intervenção psicossocial no processo de adoção. Passagens. Revista Internacional de História Política e Cultura Jurídica, 9(1), 97-118. Recuperado de https://doi.org/10.15175/1984-250320179106.

Morelli, A. B., Scorsolini-Comin, F., \& Santeiro, T. V. (2015). O "lugar" do filho adotivo na dinâmica parental: revisão integrativa de literatura. Psicologia Clínica, 27(1), 175194. Recuperado de https://doi.org/10.1590/0103-56652015000100010

Oliveira, S. V., \& Próchno, C. C. (2010). A vinculação afetiva para crianças institucionalizadas à espera de adoção. Psicologia Ciência e Profissão, 30(1), 62-84. Recuperado em 21 agosto, 2017, de http://pepsic.bvsalud.org/pdf/pcp/v30n1/v30n1a06.pdf.

Oliveira, I. F., \& Yamamoto, O. H. (2014). Definindo o campo de estudo: as políticas sociais brasileiras. In I. F. Oliveira \& O. H. Yamamoto (Orgs.). Psicologia e políticas sociais: temas em debate. Belém: Universidade Federal do Pará. 
Otuka, L. K., Scorsolin-Comin, F., \& Santos, M. A. (2012). Adoção suficientemente boa: experiência de um casal com filhos biológicos. Psicologia: Teoria e Pesquisa, 28(1), 55-63. Recuperado de https://doi.org/10.1590/S0102-37722012000100007.

Otuka, L. K., Scorsolini-Comin, F., \& Santos, M. A. (2013). Adoção tardia por casal divorciado e com filhos biológicos. Estudos de Psicologia (Campinas), 30(1) 89-99. Recuperado de https://doi.org/10.1590/S0103-166X2013000100010.

Pereira, C. R., Torres, A. R. R., Falcão, L., \& Pereira, A. S. (2013). O papel de representações sociais sobre a natureza da homossexualidade na oposição ao casamento civil e à adoção por família homoafetivas. Psicologia: Teoria e Pesquisa, 29(1), 79-89. Recuperado de https://doi.org/10.1590/S0102-37722013000100010.

Rosa, J. M., Boris, G. D., Melo, A. K., \& Santos, M. A. (2016). A construção dos papéis parentais em casais homoafetivos adotantes. Psicologia: Ciência e Profissão, 36(1), 210-223. Recuperado de https://doi.org/10.1590/1982-3703001132014.

Rossetti-Ferreira, M. C., Almeida, I. G., Costa, N. R. A., Guimarães, L. A., Mariano, F. N., Teixeira, S. C. P., \& Serrano, S. A. (2012). Acolhimento de crianças e adolescentes em situações de abandono, violência e rupturas. Psicologia: Reflexão e Crítica, 25(2). Recuperado de https://doi.org/10.1590/S0102-79722012000200021.

Santos, E. P. S. (2014). Desconstruindo a menoridade: a Psicologia e a produção da categoria menor. In H. S. Gonçalves \& E. P. Brandão (Orgs.). Psicologia Jurídica no Brasil. Rio de Janeiro: NAU.

Santos, Y. G., Scorsolini-Comin, F., \& Santos, M. A. (2013). Homoparentalidade masculina: revisando a produção científica. Psicologia: Reflexão e Crítica, 26(3), 572-582. Recuperado de https://doi.org/10.1590/S0102-79722013000300017.

Silva, M. L., \& Arpini, D. M. (2013). A nova lei nacional da adoção: desafios para a reinserção familiar. Psicologia em Estudo, 18(1), 125-135. Recuperado de https://doi.org/10.1590/S1413-73722013000100013.

Siqueira, A. C. (2012). A garantia ao direito à convivência familiar e comunitária em foco. Estudos de Psicologia (Campinas), 29(3), 437-444. Recuperado de https://doi.org/10.1590/S0103-166X2012000300013. 
Sousa, K. K., \& Paravidini, J. L. (2011). Vínculos entre crianças em situação de acolhimento institucional e visitantes da instituição. Psicologia: Ciência e Profissão, 37(3), 536553. Recuperado de https://doi.org/10.1590/S1414-98932011000300008.

Teixeira Filho, F. S. (2010). Os segredos da adoção e o imperativo da matriz bioparental. Estudos Feministas, 18(1), 241-261. Recuperado de https://doi.org/10.1590/S0104-026X2010000100015.

Valério, T. A., \& Lyra, M. C. (2014). A construção cultural de significados sobre adoção: um processo semiótico. Psicologia \& Sociedade, 26(3), 716-725. Recuperado de https:// doi.org/10.1590/S0102-71822014000300020.

Yamamoto, O. H. (2012). 50 anos de profissão: responsabilidade social ou projeto éticopolítico?. Psicologia: Ciência e Profissão, 32(spe), 6-17. Recuperado de https://doi.org/10.1590/S1414-98932012000500002.

Yamamoto, O. H., Tourinho, E. Z., Bastos, A. V. B., \& Menandro, P. R. M. (2012). Produção científica e "produtivismo": há alguma luz no final do túnel?. Revista Brasileira de Pós-Graduação, 9(18), 727-750. Recuperado de https://doi.org/10.21713/23582332.2012.v9.364.

Recebido em: 5/7/2019

Aprovado em: $25 / 9 / 2020$ 